\title{
RESTRICCIÓN A LA CAPACIDAD Y REVISIÓN DE LA DECISIÓN JUDICIAL: RESPONSABILIDAD DEL ESTADO
}

\section{RESTRICTION ON THE CAPACITY AND REVIEW OF THE JUDICIAL DECISIÓN: RESPONSIBILITY OF THE STATE}

\section{Stefania Melisa Cuello ${ }^{1}$}

DOI: https://doi.org/10.37767/2591-3476(2021)21

\section{Comentario a}

CP. E. R. c/ S. F. N. - Ordinario - Decreto de fecha 10/08/2020

Juzgado en lo Civil y Comercial, de Conciliación y Familia de $1^{\circ}$ Nominación de la Ciudad de Cosquín (Poder Judicial de la Provincia de Córdoba)

\author{
Disponible en \\ https://bit.ly/38x7EMd
}

RESUMEN:

En el presente comentario se plantea la obligación del Estado de revisar las resoluciones de limitación de capacidad de las personas en un máximo de 3 años, según el art. 40 del Código Civil y Comercial de la Nación (en adelante C.C.C.N.) y los pactos internacionales. Se resalta también la responsabilidad del Estado, tanto a nivel nacional como a nivel internacional en lo referente a la prevención de sentencias contra Argentina que implican a posteriori erogaciones de fondos públicos que podrían ser dirigidos con fines preventivos a dichas sanciones.

Se busca poner de relieve y generar un estado de alerta a todos los operadores jurídicos y sus auxiliares en su actuar diligente y de buena fe en los cargos que se desempeñan. Planteamiento de la rutinaria revisión de las limitaciones de capacidad que cada juzgado tenga en trámite.

\section{ABSTRACT}

The present comment reflects the obligatory nature of the State to check the resolutions on the limitation of capacity of individuals over a maximum period of 3 years, according to art. 40 in the CCCN (The Civil and Commercial Code of Argentina) and international agreements (Art. 75 sec.22). 
The responsibility of the State is very important in preventing sentences against Argentina that lead to emoluments which could be aimed at preventive purposes of such sanctions.

It is a call to attention to all legal practitioners and their assistants to act diligently and in good faith.

PALABRAS CLAVE: Capacidad de derecho; Revisión de la decisión; Competencia; Responsabilidad del Estado; Tratados internacionales.

KEY WORDS: Limitation of capacity; Check; Competence; Responsibility of the State; International agreements.

\section{Introducción - Planteo del caso}

El actor (en adelante P.E.R.), demanda la nulidad o readecuación del contrato que celebró en Santa María de Punilla ante el tribunal situado en la localidad de Cosquín, denunciando su domicilio real en Alta Gracia.

El actor se trata de una persona que había sido limitada en su capacidad de hecho, incluso habiéndose nombrado a su madre como curadora quien al momento de la demanda instaurada se encontraba fallecida.

Debe resaltarse, que el trámite de restricción de la capacidad se produjo bajo los lineamientos del Código Velezano en el año $1999^{2}$ por un tribunal de primera instancia de la ciudad de Córdoba.

Produce cierto estado de alerta el hecho de que la persona declarada incapaz haya instaurado una demanda de nulidad, y que además su abogado presentó un poder general para la tramitación del juicio ante el Tribunal considerado competente para dictaminar acerca de la esgrimida nulidad contractual.

La La demanda de nulidad y/o readecuación contractual promovida por P. E.R., se interpone ante el juez de la localidad de Cosquín quien se declara incompetente debido al domicilio real declarado en el líbelo introductorio (localidad de Alta Gracia) y por considerar al actor una persona con posible carácter de vulnerabilidad según las Reglas de Brasilia y la Convención sobre los Derechos de las Personas con Discapacidad -Ley 26.378-, remitiendo en consecuencia las actuaciones al tribunal del domicilio real denunciado por el actor.

\section{Aclaraciones previas.}

En el presente artículo no pretendo hacer un análisis exhaustivo del avance de la legislación en materia de incapacidad ni practicar observaciones a los pactos internacionales que complementan la regulación local al respecto, de lo cual considero que existe abundante material al alcance del lector.

Por el contrario el norte es lograr una crítica constructiva al sistema normativo que no es coherente con la realidad del país tercermundista que nos toca transitar y poner en alerta 
a los integrantes del Poder Judicial, quienes deben estar atentos al cumplimiento de las funciones que le han sido atribuidas para así conseguir la efectiva protección de los derechos de las personas vulnerables.

Además es importante traer a esta reflexión al Poder Ejecutivo, quien es el que debe proveer de fondos y recursos (humanos, económicos y edilicios) para estar a la altura de los tratados internacionales a los cuales se ha sometido la República.

\section{Restricción a la capacidad de las personas.}

En el sistema del C.C.C.N. se optó por el cambio de paradigma biologista y patrimonial del sujeto a un modelo social de la discapacidad (Avellaneda, 2018).

De esta manera el enfoque se centra en la persona vulnerable de forma global insistiendo en su integración en el núcleo familiar y en la sociedad, en su contemplación como persona autónoma (en la medida de lo posible), donde no sea objeto de discriminación y se respete su dignidad humana. Ello ha sido plasmado en la legislación fondal como la presunción de la capacidad de la persona como regla ${ }^{3}$ y su limitación como excepción.

El régimen de la capacidad de las personas y el derecho al acceso a la justicia de las personas vulnerables se encuentra reglamentado a nivel local - ley 9848-, nacional - Ley 26657- e internacional ${ }^{4}$.

Pero de nada sirve tener las mejores y más novedosas normas a nivel internacional si en la práctica los tribunales no atienden a las necesidades de la sociedad principalmente por falta de recursos que deberían ser brindados por el mismo Estado para cumplir la función que les atribuyó.

Es hora de que Argentina deje de dilapidar sus recursos económicos como consecuencia de la responsabilidad internacional que genera con su acción u omisión y empiece a invertir dichos fondos en las medidas preventivas de esas sanciones, lo cual se logra nada más ni nada menos que cumpliendo la legislación interna y la internacional que se ha adoptado como tal.

Por otro costado pretendo hacer un llamado a la responsabilidad profesional de los abogados intervinientes. Como se verá en este caso, el presunto incapaz presenta junto al profesional una carta poder de carácter general para poder llevar a cabo el juicio de readecuación o nulidad contractual, mientas que en la propia demanda el letrado relata aspectos físicos y psicológicos acerca de su cliente, apuntando de forma expresa circunstancias suficientes para considerar que dicha persona no se encuentra con la capacidad necesaria para poder dirigir sus actos ni mucho menos una acción judicial.

Por último, una simple reflexión sobre las Asesorías letradas las cuales se encuentran desatendidas y desbordadas por los requerimientos de una sociedad cada vez más demandante por la situación de crisis económica mundial que transitamos -aunque no actual-, pero que no es ajena a los deberes del control de las sentencias dictadas en relación a la capacidad de las personas, al igual que los Tribunales de las cuales emanaron.

3 Art. 31 inc. a del CCCN

4 Reglas De Brasilia Sobre Acceso A La Justicia De Las Personas En Condición De Vulnerabilidad; Convención Sobre Los Derechos De Las Personas Con Discapacidad, Convención Interamericana Para La Eliminación De Todas Las Formas De Discriminación Contra Las Personas Con Discapacidad. 
Delinear un control estricto y periódico de cada una de las personas vulnerables que han llegado lamentablemente a un estrado judicial es bastante utópico, pero es a lo que los representantes del Estado se han comprometido al firmar y ratificar los pactos internacionales. Sin mencionar las propias normas locales, las cuales parecen dibujar una panacea sobre los escasos recursos que poseen los auxiliares administrativos y funcionarios del Poder Judicial para poder apalear una realidad cada vez más dura.

\section{El caso particular.}

\section{Revisión de la restricción de la capacidad de las personas.}

La revisión judicial de la declaración de incapacidad de las personas no es creación del legislador de la ley 26.994. Ya en el código Velezano en su Art. 152 ter $^{5}$ se hacía presente que las declaraciones de inhabilitación o incapacidad no podían extenderse por más de tres años, respetando la autonomía de la voluntad del individuo en lo máximo posible.

En cambio, si es una novedad que la revisión en cuestión revista el carácter de obligatoria y cada vez que el interesado lo requiera o en un plazo máximo de 3 años ${ }^{6}$.

Es novedoso el tiempo establecido de modo genérico, cuestión que no se repite en la legislación internacional, pero es importante señalar que es una obligación asumida en la Convención sobre los Derechos de las Personas con Discapacidad (Seda, 2018), aunque esta última no fije plazos automáticos.

Esta obligación queda a cargo de los apoyos designados, juez interviniente - quién dictó la sentencia de limitación de la capacidad - o Asesores Letrados, como ampliaré seguidamente. Para la persona limitada en su capacidad, es un derecho que posee el solicitar dicha revisión cuando lo considere pertinente junto con sus auxiliares técnicos y complementarios.

Esta nueva legislación del C.C.C.N., no hace más que reconocer los instrumentos internacionales firmados y ratificados por la República Argentina, como son la Convención Americana sobre Derechos Humanos (1984), Convención Interamericana para la Eliminación de todas las formas de Discriminación contra las Personas con Discapacidad - CIEDPD(2000), la Convención sobre los Derechos de las Personas con Discapacidad (2008) y las Reglas De Brasilia sobre acceso a la justicia de las personas en condición de vulnerabilidad.

Las personas con algún grado de discapacidad son categorizadas a partir de las Reglas de Brasilia como personas en situación de vulnerabilidad. Ello conlleva de forma directa a un cuidado y atención especial en los procedimientos legales donde se encuentre inmersa una persona que sufra algún tipo de discapacidad o limitación en sus facultades.

"1.- Concepto de las personas en situación de vulnerabilidad: Se consideran en condición de vulnerabilidad aquellas personas que, por razón de su edad, género, estado físico o mental, o por circunstancias sociales, económicas, étnicas y/o culturales, encuentran especiales dificultades para ejercitar con plenitud ante el sistema de justicia los derechos

\footnotetext{
5 Artículo 152 ter Código Velezano: Las declaraciones judiciales de inhabilitación o incapacidad deberán fundarse en un examen de facultativos conformado por evaluaciones interdisciplinarias. No podrán extenderse por más de TRES (3) años y deberán especificar las funciones y actos que se limitan, procurando que la afectación de la autonomía personal sea la menor posible.

6 ARTICULO 40 CCCN.- Revisión. La revisión de la sentencia declarativa puede tener lugar en cualquier momento, a instancias del interesado. En el supuesto previsto en el artículo 32, la sentencia debe ser revisada por el juez en un plazo no superior a tres años, sobre la base de nuevos dictámenes interdisciplinarios y mediando la audiencia personal con el interesado.
} 
reconocidos por el ordenamiento jurídico".

Por otra parte, nuestra Constitución Nacional en su Art. 75 inc. 23 identifica a los derechos humanos de tercera generación, la cual identifica a grupos de personas vulnerables integrados por niños, mujeres, adultos mayores y personas con discapacidad, quienes merecen que se les garantice la igualdad real de oportunidades y trato, el pleno goce y ejercicio de los derechos reconocidos por esta y por los tratados internacionales vigentes sobre Derechos Humanos (Vittori, 2019).

\section{A. Revisión del dictamen al pedido del interesado o de oficio.}

Es interesante el aporte que hace la doctrina al mencionar que en el plano de la realidad, la revisión de la limitación de la capacidad es en sí una supervisión judicial permanente (Seda, 2018).

Lo que se tiene en cuenta al momento de volver sobre el caso particular del incapaz, son cuestiones que distan mucho de la evaluación médico objetiva, sino que además debe reverse el vínculo con sus apoyos, la mayor o menor inserción que se ha producido en la sociedad e incluso en el campo laboral, y la estabilidad emocional e intelectual del sujeto, abarcando de esta manera un análisis holístico de su persona y circunstancias particulares.

En cuanto a los sujetos legitimados para solicitar la revisión de la limitación de capacidad dictaminada, pueden ser el juez interviniente, curadores, los asesores letrados que hayan tenido participación o incluso el mismo incapaz. ${ }^{8}$

Tal es la obligación que posee el Estado para las personas que han sido limitadas en su capacidad acerca de la revisión de lo oportunamente resuelto, que el C.C.C.N. en su Art. 40 ultima parte, pone en cabeza del Ministerio Público Fiscal el deber de instar la revisión en el caso de que no se haya efectuado?.

Es importante señalar en este punto a los fines de la interpretación de la legislación de fondo, el Tribunal Superior realizó una aclaración reglamentaria en relación con el art. 103 del C.C.C.N. Estableciendo que en el ámbito del Poder Judicial de Córdoba, cuando el referido art. 103 alude al Ministerio Público, se debe entender que hace referencia a los Asesores Letrados, quienes son los funcionarios encargados de la defensa de las personas. (Ceballos Chiappero, 2018)..$^{10}$

\section{B. Posibilidad de revisión de la declaración de incapacidad por tercero interesado.}

El C.C.C.N. nada dice respecto de si la declaración de incapacidad o su revisión puede ser solicitada por terceros que no tengan parentesco o convivencia con el presunto incapaz, a diferencia del Art. 144 inc. 5 del Código Velezano.

Es en este punto en donde es posible preguntarse acerca de la seguridad jurídica y comercial que esta novel legislación trae respecto del tema de las incapacidades de las personas.

\footnotetext{
7 Reglas de Brasilia. Sección 2a -- Beneficiarios de las Reglas 1.- Concepto de las personas en situación de vulnerabilidad.

8 De más está advertirle al lector, que para ello deberá contar con el asesoramiento jurídico necesario, ya sea provisto de forma privada o por medio de la asistencia técnica que ejerza la Asesoría de turno.

9 ART. 40.- Revisión. (...) Es deber del Ministerio Público fiscalizar el cumplimiento efectivo de la revisión judicial a que refiere el párrafo primero e instar, en su caso, a que ésta se lleve a cabo si el juez no la hubiere efectuado en el plazo allí establecido

10 Acuerdo Reglamentario No 1305, Serie “A”, del $1^{\circ}$ de setiembre de 2015.
} 
El régimen protectorio ha sido pensado, diseñado y (mal) aplicado en miras solamente del presunto incapaz.

A estas alturas cabe preguntarse, ¿Qué sucede con aquel tercero de buena fe que contrata con un incapaz del cual su falta de capacidad no es manifiesta?. Suponiendo el caso que sea un contrato no abusivo y mediando buena fe, ¿El Estado puede obligar a un tercero a mantener un contrato celebrado por una persona que no cuenta con los recursos para comprender sus actos? ¿Puede un tercero interesado recurrir a la justicia para que revea la capacidad de una persona que con la cual contrató y eventualmente declararse la nulidad del contrato?

Y es aquí donde se abren innumerables preguntas hoy sin respuesta legal definida.

Me atrevo a decir que en pos de la seguridad jurídica, aquel tercero perjudicado por haber contratado de buena fe con un incapaz podría acudir al Poder Judicial para que este tome intervención en el caso, siendo necesariamente el cuerpo de Asesores quien asista y complemente la capacidad procesal de la persona con discapacidad de encontrarse en un estado de vulnerabilidad, más allá de que si el presunto incapaz cuenta con defensa técnica privada por poseer los recursos necesarios para ello.

No repercute de buena manera a la realidad contractual que un tercero que actuó de buena fe quede ligado hasta la finalización del contrato con una persona que no solo no comprenda la envergadura del acto sino que muy probablemente no cumpla con sus contraprestaciones y una pérdida patrimonial del tercero.

La situación de que la limitación de capacidad se encuentre registrada en el Registro Civil y de Capacidad de las personas no es oponible en la cotidianeidad de los contratos domésticos como es el caso que se examina, donde las partes no se requieren mutuamente copias de sus actas de nacimiento para llevar a cabo un determinado negocio jurídico.

El derecho se encuentra en un cimbronazo en el cual la letra escrita desde antaño acerca del buen uso y las buenas costumbres debe pasar al plano de los hechos comunes y cotidianos y ser los legisladores y auxiliares jurídicos quienes den una pincelada de realidad a la letra de la legislación y a los hechos que en la sociedad acontecen.

\section{Responsabilidad del Estado.}

La situación planteada por la resolución analizada lleva directamente a repensar la responsabilidad del Estado de cumplir con su propia normativa.

En el caso de marras han pasado exactamente 22 años desde que el pretenso actor ha sido declarado incapaz con una curatela dispuesta en cabeza de una persona que al momento de la acción civil se encuentra fallecida.

Ya he hecho mención a la obligación que tiene el cuerpo de Asesores sobre las limitaciones de capacidad en las cuales haya tomado intervención, pero no es menos cierto que el juzgado que dictó la resolución no puede desentenderse una vez declarada la restricción de capacidad. Incluso el C.C.C.N. y la Convención sobre los Derechos de las Personas con Discapacidad lo tornan obligatorio para los sujetos partícipes en la justicia. 
Considero una mejora extraordinaria que el Art. 40 del CCCN haya dispuesto expresamente la obligatoriedad de la revisión de la limitación de capacidad, ya que tomada con seriedad y puestos los recursos económicos y humanos necesarios, prevendrá situaciones como la de marras en un futuro no muy lejano.

\section{A. Responsabilidad interna del Estado.}

Es imposible no reflexionar acerca de cuál es el grado de responsabilidad que tiene el Estado no solo para con la persona presuntamente incapaz (la cual en el caso ha quedado totalmente desamparado ya que su curadora se encuentra fallecida), sino para con el resto de la sociedad, que no tiene manera de poder constatar una limitación de capacidad de vieja data y donde el comportamiento de la contraparte no demuestra ningún impedimento legal al momento de contratar.

El Estado debido al Art. 40 del C.C.C.N. y la Convención sobre los Derechos de las Personas con Discapacidad tiene la obligación de rever cada una de los dictámenes que se efectúen sobre las personas en cuanto a la restricción de su capacidad. No es necesario que el procedimiento ocurra a instancia de parte, o de un tercero perjudicado por el accionar del incapaz. Es el cuerpo de Asesores y el Tribunal interviniente quien debe tener precaución sobre las resoluciones a las ha arribado.

Lamentablemente el discurso de la falta de recursos es harto conocido, pero no por ello el Estado se encuentra en condiciones de incumplir sus propias normas perjudicando al ciudadano de buena fe. Es cuestión de los tres poderes de la República y de cada una de las provincias articulen los medios necesarios para llevar un estricto control de la situación analizada.

De continuar con este tipo de actividades reacias a revisar todas las sentencias de las personas declaradas incapaces, se está violentando flagrantemente los Arts. 16 y 18 de la Constitución Nacional, juntamente con la ley nacional y provincial de Salud mental que tienen el carácter de ser legislación de tendencia, pero letra muerta.

No considero inmanejable la cantidad de limitaciones de capacidad que los tribunales Civiles y Comerciales o de fuero múltiple del interior de la provincia tienen a su cargo y no deja de ser una obligación del cargo que se desempeña.

Se puede discutir el tema de los recursos puertas adentro del Estado; pero para con la sociedad el Poder Judicial tiene una obligación legal, ética y moral de cumplir su función maximizando su eficacia y eficiencia. Además, es una realidad que el Sistema de Administración de Causas, ha venido a simplificar la búsqueda y control por tipo de juicios de estos procedimientos.

\section{A.1. Nulidad relativa.}

Considero correcta la decisión del juez de Cosquín por ante quien se impetra la acción de nulidad o readecuación de cláusulas contractuales en reparar que el actor posiblemente no cuente con las capacidades necesarias para entender sus actos y necesite el sistema de representación y apoyo previsto por la legislación. Ello hace a que se deba resolver en primer lugar esta situación de incertidumbre sobre la capacidad del actor, para luego poder expedirse en caso de que la incapacidad cese o disminuya al efecto de que P.E.R. pueda comprender sus actos, y posteriormente poder analizar y decidir la cuestión planteada respecto de la nulidad o readecuación de cláusulas contractuales del contrato de 
locación efectuado.

De haberse continuado con el juicio de tipo ordinario impetrado por el actor incapaz, se hubiesen violentado derechos como el debido proceso, el contradictorio y la defensa en juicio.

Existiendo una sentencia de limitación de capacidad, no se puede presumir que la misma ha cesado por el mero transcurso del tiempo. No hay que olvidar que la tutela judicial efectiva es un derecho humano fundamental, el cual no termina con el dictado de la limitación de capacidad y asignación de una curadora.

Una vez resuelta la cuestión de la capacidad del actor, la nulidad a la cual se podría afrontar el contrato base de la acción ordinaria es una nulidad de tipo relativa. Ya que el fin de la normativa es la protección del incapaz.

Con este tipo de nulidad prevista y el sujeto protegido por la legislación no estoy de acuerdo. Considero que un tercero contratante de buena fe una vez declarada el mantenimiento de las restricciones de la capacidad, puede y debe solicitar la anulación del acto. No debe dejarse de lado que las personas se encuentran insertas en una sociedad que necesita de ciertos parámetros de seguridad jurídica - y comercial- para poder funcionar.

\section{B. Responsabilidad internacional}

El apartado anterior tiene clara relación con la responsabilidad internacional de Argentina, ya que ha firmado tratados internacionales en donde se compromete al efectivo cumplimiento de los Derechos Humanos reconocidos por dichos instrumentos y por su real aplicación.

Es alarmante el podio en el cual se encuentra nuestro país en cuanto a sentencias dictadas por la Corte Internacional de Derechos Humanos, luego de Venezuela, Colombia y Perú, si tenemos en cuenta el índice poblacional de los nombrados - el cual nos cercamos por 10 millones a Colombia-, o con Brasil, el cual en 2021 solo tiene 14 casos de sentencia con 211 millones de habitantes, mientras que argentina tiene 34 sentencias con 44 millones $^{11}$.

Más allá de la condena internacional que sufre Argentina frente a casos donde se violenten Derechos Humanos, debe preocupar el gasto público - a largo plazo- en el cual se incurre cada vez que se condena al Estado.

Las sumas dinerarias son muy importantes, y aunque normalmente se abonen en bonos junto a un dictamen de tipo reparativo, son emolumentos que bien pueden invertirse en que el sistema diseñado por el legislador funcione y cumpla su función.

Para poner un ejemplo específico de responsabilidad internacional por un caso de una persona con padecimientos mentales en el país de Brasil, traigo a colación el fallo de la CIDH "Ximenes Lopes Vs. Brasil". En el mencionado - y trágico- hecho el Estado de Brasil debió reconocer ante la organización internacional la precariedad del sistema de atención de salud mental al cual la presunta víctima fue sometida al momento de los hechos, lo que constituyó una violación del artículo 4 de la Convención. La Corte expresó:

138. “La posición especial de garante que asume el Estado con respecto a personas 
que se encuentran bajo su custodia o cuidado, a quienes el Estado tiene la obligación positiva de proveer las condiciones necesarias para desarrollar una vida digna"12,

147. "La obligación de garantizar los derechos humanos consagrados en la Convención no se agota con la existencia de un orden normativo dirigido a hacer posible el cumplimiento de esta obligación, sino que comporta la necesidad de una conducta gubernamental que asegure la existencia, en la realidad, de una eficaz garantía del libre y pleno ejercicio de los derechos humanos. ${ }^{13 "}$

\section{Responsabilidad profesional del abogado litigante.}

Al analizar el fallo no podemos olvidarnos de que el abogado que firma la demanda junto con el actor P.E.R., presentó una carta poder general dada por su mandante, presunto incapaz.

Cabe destacar que la incapacidad de la cual pretendió valerse para lograr una sentencia favorable respecto de la nulidad contractual haciendo hincapié en el débil carácter de su representado, fue lo que advirtió al tribunal de estar frente a un actor que posiblemente cuente con sus facultades mentales alteradas.

Hoy la justicia se encuentra vapuleada por sus demoras, en ocasiones por sus resoluciones no muy felices, y sobre todo por sus operarios. No se debe olvidar que el deber de actuar conforme al derecho no solo es atribuible al tribunal interviniente, sino al profesional que comparece ante los estrados judiciales.

Es indescifrable qué es lo que pretendió el letrado al momento de impetrar una demanda en la cual cuasi diagnosticaba a su cliente y luego el acompañamiento de la carta poder, al menos analizándolo desde la lógica y la buena fe.

4. Otro aspecto a analizar del decreto del Juzgado en lo Civil y Comercial, de Conciliación y Familia de $1^{\circ}$ Nominación de la ciudad de Cosquín.

No queda claro del decreto analizado, más allá de la denuncia del actor de su domicilio en la localidad de Alta Gracia, que se haya tomado otro tipo de recaudo antes de decidir la remisión de la causa a dicha sede jurisdiccional. En búsqueda de la protección al derecho de acceso a la justicia y derecho de defensa del actor presunto incapaz, hubiese sido conveniente - de no haberse realizado- una consulta al padrón electoral provincial, a los fines de verificar el domicilio del actor.

No hay que olvidar que la sentencia de limitación de capacidad fue dictaminada en la ciudad de Córdoba en el año 1999, y quizás las vicisitudes de la vida no se reflejen en la demanda impetrada. El juez firmante solo aduce lo mencionado por el actor y su patrocinante, por lo que al existir una persona en condiciones de vulnerabilidad, el Tribunal debería haber realizado una investigación objetiva de oficio a los fines de decidir e incluirlo como fundamento del decreto de remisión de los obrados.

De esta manera, no solo se ejerce el fin tuitivo del C.C.C.N. y del Ac. Reg. 1619 Serie A de fecha 10/03/2020 dedicado a los Protocolos de actuación para el Acceso a la Justicia 
respecto de R.E.F., sino que se tutela la seguridad jurídica del tercero contratante, hasta ahora presumible de buena fe.

Si el actor incapaz no tuviere de hecho domicilio real en Alta Gracia tal como se denunció en la demanda, no puede dejar de pensarse en una maniobra dilatoria del abogado patrocinante.

En el caso de que la mencionada búsqueda haya arrojado resultado arrojase resultado negativo, considero que el juez de Cosquín, debió remitir las actuaciones a la ciudad de Córdoba, por ser el Tribunal originario donde se dictó la limitación de la capacidad de R.E.F., y la cual debe analizarse nuevamente.

\section{Una solución, ¿Utópica?}

En tiempos en que hemos sido apremiados por la modernidad y en los cuales la realidad de crisis mundial nos ha llevado a un adelanto tecnológico e informático que preveíamos para dentro de 10 años, hoy considero posible que los juzgados en donde se tramitan limitaciones de capacidad de personas tienen la posibilidad de llevar un fácil registro y control de sus actuaciones y del tiempo que transcurre respecto de la decisión arribada y su posible revisión.

No con ello quiero expresar que absolutamente todas las sentencias deben ser revisadas con la presencia del incapaz. Existen casos en que el diagnóstico médico de la persona no será reversible ni progresará más allá de lo evaluado por el equipo técnico y lo apreciado por el propio juez en la audiencia del 839 del C.P.C.C.

Por ello considero una solución posible que el Tribunal que tenga a cargo este tipo de juicios los revise con criterio de buen juzgador y según tiempo transcurrido; y que en absolutamente todos los casos designe de oficio según los parámetros señalados, o a pedido del curador, asesores o el propio incapaz, una audiencia prevista por el Art. 58 del C.P.C.C., a los fines de analizar la situación en particular, no siendo necesaria la presencia del incapaz cuando el diagnóstico es indubitable. Sí es necesario que concurran los asesores y los curadores intervinientes. Esto, no solo por el hecho de que se reevaluará los márgenes de la limitación en sí misma, sino porque se prevendrían casos como el de marras, en donde la curadora se encuentra fallecida.

En el caso de que en esta primera audiencia surja una situación gris, en donde no sea claro el estado de la persona con discapacidad, podrá ordenar una segunda, ya esta vez con la presencia del incapaz.

Aquí me detengo para resaltar la importancia de que tiene el contacto del juez con la persona en estado de vulnerabilidad, y de la posibilidad del juzgador de salir de su despacho para efectivizarlo. La re victimización no solo se evita no trayéndolo nuevamente a un palacio de justicia donde en muchas oportunidades podemos ver a personas sufriendo un ambiente poco propicio para quienes poseen alteraciones mentales, sino también puede recurrirse a que sea el juez y los asesores quienes se desplacen hasta el sujeto.

Como dije más arriba, la cuestión de los recursos temporales, materiales y económicos, son un problema que el Poder Judicial deberá arreglar con el Poder Ejecutivo; pero para con la sociedad tanto empleados, funcionarios y magistrados tenemos la obligación de 
poder satisfacer sus necesidades al menos en la parte que nos debemos ocupar.

Volviendo al caso analizado ha sido producto del buen ojo del juzgador, quien advirtió que el actor probablemente no haya estado con las facultades que el negocio que se llevó a cabo y la posterior anulación requerida necesiten, pero es necesario empezar a tener una sistematización en la forma de funcionar del Poder Judicial para que en la práctica el Estado cumpla con las leyes dictadas y ratificadas.

\section{Conclusión}

La resolución traída en este comentario es de suma importancia para determinar el mal estado en el cual nos encontramos frente a las personas en calidad de vulnerables.

No es concebible que en un Estado de derecho hayan pasado 22 años sin una revisión de la sentencia restrictiva de la capacidad, y menos aun cuando la persona designada curadora, se encuentra fallecida.

Hemos dejado como República a un presunto incapaz desprotegido y a la deriva de sus decisiones que quizá requieran un acompañamiento para protegerse a sí mismo y a sus bienes.

Por otro lado, le hemos fallado al ciudadano demandado quien posiblemente en su presumible buena fe - hasta que se demuestre lo contrario-, ha contratado con una persona que no se encontraba en condiciones jurídicas.

El buen ojo del juzgador ante quien se interpuso la demanda y los dichos grotescos del abogado sobre el actor en cuanto a sus presuntas facultades mentales y percepción física, han hecho posible que se encienda una alarma de protección a la parte más débil del contrato y así no solo se active un proceso para determinar su capacidad o no en función del contrato de marras, sino en cuanto poder proveer los medios y apoyos que la persona necesite para poder desarrollarse en cumplimiento de la normativa local, nacional e internacional.

\section{REFERENCIAS BIBLIOGRÁFICAS}

- Avellaneda, M. P.-G. (2018). La declaración de capacidad restringida de la persona y la mirada interdisciplinaria del juez. La Ley, 29. Obtenido de TR LALEY AR/DOC/3544/2018

- Ceballos Chiappero, P. F. (22/8/2018). La actuación principal del Ministerio Público ante la inacción de los representantes legales. Semanario Jurídico, 2169, 309.

- Neder, M. G., El acceso a la justicia de personas con restricción a la capacidad: vulnerabilidad, modelo social de discapacidad y tutela procesal diferenciada, Tesis de Máster, Universidad Siglo 21.

- Seda, J. A. (2018). La actuación procesal de personas incapaces y con capacidad restringida en el Código Civil y Comercial. La Ley, 591. Obtenido de TR LALEY AR/DOC/2390/2018 - Vittori, V. V. (10/5/2019). Derechos humanos de la tercera generación: capacidad restringida versus autonomía, dignidad e. La Ley, 139. Obtenido de TR LALEY AR/DOC/2156/2018 